\title{
PENINGKATAN KERJA PADA AIR CONDITIONER DALAM MENJAGA SUHU RUANG AKOMODASI DI MV. GLOVIS DAYLIGHT
}

\author{
Rizqi Aditya Pratama ${ }^{a}$, Dwi Prasetyo \\ ${ }^{a}$ Taruna Program Studi Teknika PIP Semarang \\ ${ }^{\mathrm{b}}$ Dosen Program Studi Teknika PIP Semarang \\ rizqipratama31@gmail.com
}

\begin{abstract}
ABSTRAK
Mesin pendingin adalah salah satu permesinan bantu yang bekerja untuk menghasilkan suhu atau temperature dingin guna mendinginkan ruangan diatas kapal serta memberi rasa nyaman pada crew kapal.

Metode yang digunakan dalam penelitian ini adalah metode kualitatif dengan pendekatan metode Fishbone Analysis, menemukan penyebab utama kurang optimalnya kerja Air Conditioner, menemukan dampak kurang optimalnya kerja Air Conditioner serta mengkombinasikannya dengan metode Fault Tree Analysis untuk menemukan upaya dari permasalahan paling mendasar (Basic Event).

Hasil penelitian ini menemukan faktor utama yang mengakibatkan kurang optimalnya kerja Air Conditioner yaitu terjadinya endapan pada pipa-pipa kondensor sehingga mengganggu proses kondensasi. Hal tersebut diakibatkan karena kotornya LT Cooler. Dampak yang terjadi adalah crew merasa kurang nyaman ketika berada disuatu ruangan, timbul kerugian yang cukup besar baik dampak internal maupun eksternal. Kemudian upaya yang dilakukan yaitu melakukan perawatan pada permesinan sesuai dengan Plan Mantenance System serta dilakukan pengetesan air pada LT Cooler.
\end{abstract}

Kata kunci: Mesin Pendingin, Air Conditioner, Metode Fishbone dan Metode Fault Tree Analysis.

\section{PENDAHULUAN}

Agar pengoperasian kapal dapat berjalan dengan baik tentu juga perlu adanya perawatan yang baik terhadap permesinan di kapal, baik mesin induk maupun permesinan bantu yang menunjang pengoperasian mesin induk diatas kapal. Salah satu permesinan bantu tersebut adalah Air Conditioner. Air Conditioner adalah salah satu jenis permesinan bantu yang berada diatas kapal yang berfungsi untuk mendinginkan udara dengan cara mensirkulasikan gas refrigerant yang di tekan dan dihisap oleh Kompresor.

Berdasarkan pengalaman yang penulis alami ketika melaksanakan praktek laut selama dua belas bulan di MV. Glovis Daylight. Penulis mengalami 4 musim yaitu musim dingin, musim semi, musim gugur dan musim

panas. Ketika memasuki musim panas suhu ruangan di akomodasi sangatlah panas sehingga membuat crew kapal merasa tidak nyaman, yang seharusnya suhu ruangan sekitar $22^{0} \mathrm{c}$ sampai dengan $25^{\circ} \mathrm{c}$ naik menjadi $30^{\circ} \mathrm{c}$ sampai dengan $35^{\circ} \mathrm{c}$ dan ketika memasuki musim dingin suhu ruangan di akomodasi sangatlah dingin yaitu mencapai $15^{\circ} \mathrm{c}$ sampai dengan $18^{\circ} \mathrm{c}$. Dalam hal ini ada berbagai macam faktor, gangguan, serta masalah yang menyebabkan kerja pada Air Conditioner kurang maksimal sehingga suhu di akomodasi tidak normal. 
Peningkatan Kerja Pada Air Conditioner Dalam Menjaga Suhu Ruang Akomodasi Di MV.Glovis Daylight

\section{Rizqi Aditya Pratama ${ }^{a}$, Dwi Prasetyo}

Dalam hal ini penulis dapat merumuskan perumusan masalah sebagai berikut:

1. Faktor-faktor penyebab kurang optimalnya kerja pada Air Conditioner MV. Glovis Daylight guna menjaga suhu ruang di Akomodasi Kapal?

2. Bagaimanakah dampak kurang optimalnya kerja pada Air Conditioner MV. Glovis Daylight?

3. Bagaimanakah upaya meningkatkan kurang optimalnya kerja pada Air Conditioner MV. Glovis Daylight?

\section{METODE}

A. Waktu dan Tempat Penelitian

1. Waktu Penelitian

Penelitian dilakukan selama satu tahun lebih satu minggu ketika masa praktek laut berlangsung, yaitu tehitung dari sign on pada tanggal 14 Agustus 2017 di Samarinda, Indonesia sampai dengan sign off pada tanggal 17 Agustus 2018 di Samarinda, Indonesia.

2. Tempat Penelitian

Adapun tempat penelitian yang dilaksanakan di kapal penulis melaksanakan praktek laut yaitu di atas kapal MV. Glovis Daylight yaitu kapal niaga yang berjenis Bulk Carier kapal buatan tahun 2015 yang merupakan kapal yang dioperatori perusahaan pelayaran Korea Selatan yaitu HYUNDAI GLOVIS CO.,LTD.

B. Sumber Data

Data artinya informasi yang didapat melalui pengukuranpengukuran tertentu, untuk digunakan sebagai landasan dalam menyusun argumentasi logis menjadi fakta. Sedangkan fakta itu sendiri adalah kenyataan yang telah diuji kebenarannya secara empirik, antara lain melalui analisis data.
Menurut macam atau jenisnya, data dibedakan menjadi dua, yaitu:

1. Data Primer

Menurut

(2009:245) Data primer merupakan sumber-sumber dasar yang merupakan bukti atau saksi utama dari kejadian yang lalu, dimana sumber primer adalah tempat atau gudang penyimpanan yang original dari data sejarah. Dalam hal ini, data-data pada penelitian ini diperoleh dengan cara survey dan terjun secara langsung pada objek penelitian yang diteliti pada saat diatas kapal, yaitu dengan cara memahami dan mengamati secara langsung di lokasi penelitian.

2. Data Sekunder

Menurut

Sugiyono (2009:225)Data sekunder adalah sebuah data yang memiliki suatu bentuk nyata, dari suatu penelitian yang dapat dijadikan acuan penelitian, dan data sekunder diperoleh dari kajiankajian pustaka yang diambil dari buku.

C. Metode Pengumpulan Data

Pengumpulan data dimaksudkan untuk memperoleh bahan-bahan yang relevan, akurat dan nyata. Oleh karena itu penulis mempergunakan suatu pengumpulan data lebih dari satu, sehingga data-data tersebut dapat saling melengkapi satu sama lain. Teknik pengumpulan data tersebut antara lain :

1. Observasi

Metode observasi ini adalah suatu usaha ilmiah untuk mengumpulkan data yang dilakukan secara sistematis terhadap subjek pengamatan dengan metode standar. Tujuan 
penulis mengadakan observasi adalah agar mengerti akan keadaan objek yang dijadikan topik yaitu Air Conditioner secara menyeluruh dan langsung, untuk memberi kesesuaian antara keterangan-keterangan yang diperoleh dengan keadaan yang sebenarnya terjadi. Metode ini penulis lakukan bedasarkan pengalaman selama praktek berlayar di MV. Glovis Daylight.

2. Wawancara

Wawancara ialah cara pengumpulan data dengan mengadakan tanya jawab langsung kepada perantara yang mengetahui persoalan dari objek yang diteliti. Metode wawancara ini penulis menanyakan langsung kepada Third Engineer selaku perwira yang bertanggung jawab untuk kelancaran kerja dari Air Conditioner tersebut. Tujuan pokok dari wawancara adalah untuk memperoleh data-data yang aktual secara langsung mengenai Air Conditioner.

3. Metode Dokumentasi

Dokumentasi yaitu merupakan salah satu teknik pengumpulan data yang digunakan oleh penulis dengan mencatat dan mengambil gambar bagian-bagian mesin serta saat mengerjakan perbaikan dan perawatan terhadap suatu permesinan dan segala sesuatu yang berhubungan dengan Air Conditioner dan sistemnya. Dokumen tersebut seperti buku petunjuk (Instruction Manual Book) dan Engine Log Book.

4. Studi pustaka

Studi pustaka adalah suatu pembahasan yang berdasarkan pada catatan dari jurnal mesin, yang bertujuan untuk memperkuat materi pambahasan maupun sebagai dasar dalam menganalisa dan mendesain suatu struktur.

D. Teknis Analisis data

Dalam penulisan teknik analisa data ini, penulis menggunakan dua metode analisa dan pengolahan data yaitu:

\section{Metode Analisis Fishbone}

Diagram Fishbone adalah salah satu metode yang digunakan dalam meningkatkan kualitas atau diagram SebabAkibat/Cause Effect diagram yang menggunakan data verbal (Non-Numerical) atau data kualitatif atau diagram Fishbone (tulang ikan). Fungsi dasar diagram Fishbone adalah untuk mengidentifikasi dan mengorganisasi penyebabpenyebab yang mungkin timbul dari efek spesifik dan kemudian memisahkan akar penyebabnya. Pendekatan yang digunakan untuk menjabarkan pada metode Fishbone Analysis adalah:
a) Manusia
b) Nature (Alam)
c) Material
d) Method

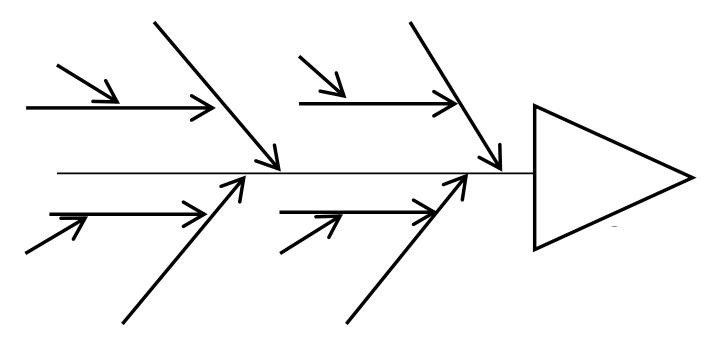

Gambar Diagram Fishbone

2. Metode Analisis Fault Tree Analysis

Fault Tree Analysis adalah suatu teknik yang digunakan untuk mengidentifikasi resikoresiko yang menjadi peran terhadap terjadinya kegagalan. Metode ini dilakukan dengan pendekatan yang bersifat Top 
Peningkatan Kerja Pada Air Conditioner Dalam Menjaga Suhu Ruang Akomodasi Di MV.Glovis Daylight

Rizqi Aditya Pratama ${ }^{a}$, Dwi Prasetyo

Down, yang diawali dengan asumsi kegagalan dari kejadian puncak (Top Event) kemudian merinci sebab-sebab suatu Top Event sampai pada suatu kegagalan dasar (Root Cause).

Kemudian gerbang logika menggambarkan kondisi yang memicu terjadinya kegagalan, baik kondisi tunggal maupun berbagai macam kondisi. Konstruksi dari Fault Tree Analysis meliputi gerbang logika yaitu gerbang AND dan OR. Setiap kegagalan yang terjadi dapat digambarkan ke dalam suatu bentuk pohon analisa kegagalan dengan memindahkan komponen kegagalan ke dalam bentuk simbol (Logic Transfer Components) dan Fault Tree Analysis.

Tabel Istilah-istilah dalam Fault Tree Analysis

\begin{tabular}{|c|c|}
\hline Istilah & Keterangan \\
\hline Event & 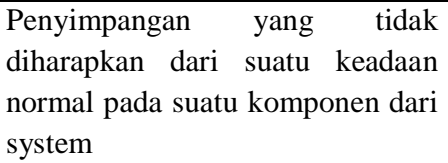 \\
\hline Top Event & $\begin{array}{l}\text { Kejadian yang dikehendaki pada } \\
\text { "puncak" yang akan diteliti lebih } \\
\text { lanjut ke arah kejadian dasar } \\
\text { lainnya dengan menggunakan } \\
\text { gerbang logika untuk menentukan } \\
\text { penyebab kegagalan }\end{array}$ \\
\hline Logic Event & $\begin{array}{l}\text { Hubungan secara logika antara } \\
\text { input dinyatakan dalam AND dan } \\
\text { OR }\end{array}$ \\
\hline $\begin{array}{l}\text { Transferred } \\
\text { Event }\end{array}$ & $\begin{array}{l}\text { Segitiga yang digunakan simbol } \\
\text { transfer. Simbol ini menunjukkan } \\
\text { bahwa uraian lanjutan kejadian } \\
\text { berada di halaman lain. }\end{array}$ \\
\hline $\begin{array}{l}\text { Undeveloped } \\
\text { Event }\end{array}$ & $\begin{array}{l}\text { Kejadian dasar (Basic Event) yang } \\
\text { tidak akan dikembangkan lebih } \\
\text { lanjut karena tidak tersedianya } \\
\text { informasi. }\end{array}$ \\
\hline Basic Event & $\begin{array}{l}\text { Kejadian yang tidak diharapkan } \\
\text { yang dianggap sebagai penyebab } \\
\text { dasar sehingga tidak perlu } \\
\text { dilakukan analisa lebih lanjut. }\end{array}$ \\
\hline
\end{tabular}

Jadi secara umum metode Fault Tree Analysis adalah sebuah metode menyelesaikan kasus apabila terjadi sesuatu kegagalan dengan Basic Events yang muncul dan diuraikan dari setiap indikasi kejadian puncak (Top Event).

Metode ini dapat dikembangkan secara lanjut dengan metode probabilitas dari setiap akar permasalahan dari Basic Event menjadi Top Event.

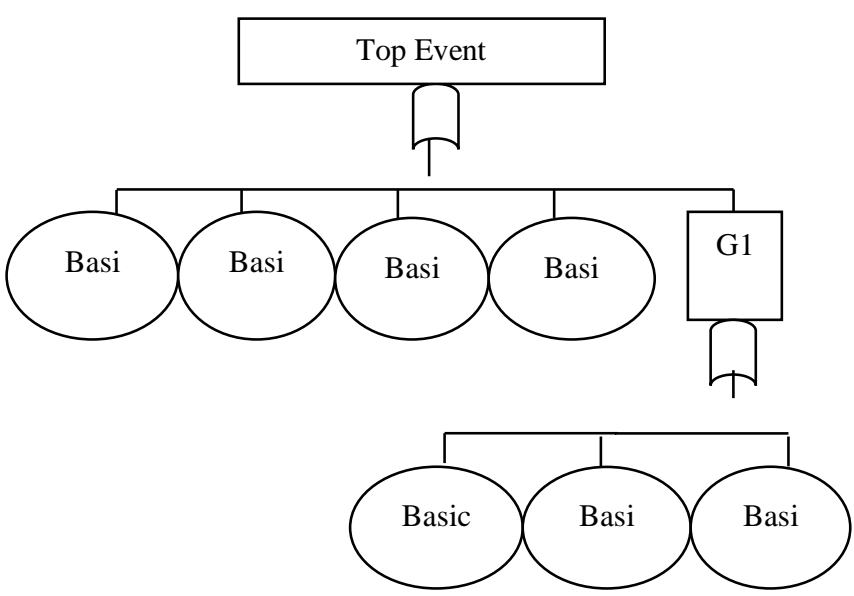

Bagan Fault Tree Analysis

Persilangan metode penelitian adalah penggabungan antara dua metode penelitian menjadi satu yang bertujuan untuk membantu penulis dalam menemukan akar pokok dari permasalahan yang terjadi.

Dari kedua metode terdapat tiga poin utama yang perlu kita perhatikan, yaitu; mesin, manusia, dan alam. Ketiga poin ini adalah inti atau pokok-pokok dari kedua metode diatas yang berikutnya penulis susun dalam sebuah gambar akhir dari metode penelitian dibawah ini.

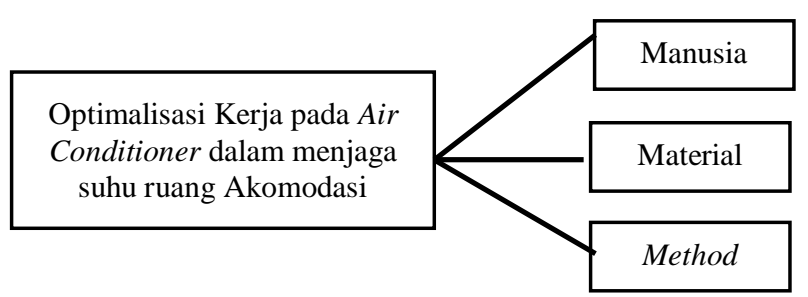




\section{HASIL DAN PEMBAHASAN}

A. Gambaran Umum Objek Yang Diteliti

Objek penelitian adalah bahan permasalahan yang terdapat pada suatu penelitian yang akan dikupas atau dibahas lebih terperinci pada analisa penelitian. Dalam penelitian ini peneliti menggunakan obyek dimana peneliti melaksanakan penelitian yaitu di MV. Glovis Daylight yang merupakan salah satu kapal bulk carrier milik perusahaan pelayaran korea yaitu HYUNDAI GLOVIS CO.

B. Analisa Masalah

Dari hasil penelitian yang dilakukan ketika melaksanakan praktek laut yaitu pada tanggal 14 April 2018 saat kapal sedang melakukan pelayaran dari Youngheoung, Korea Selatan menuju Gladstone, Australia terjadi permasalahan pada Air Condtioner yang menyebabkan Air Conditioner tidak bekerja dengan optimal. Dari permasalahan tersebut, Penulis mengkaji dan menganalisis tentang optimalisasi kerja pada Air Conditioner dalam menjaga suhu ruang akomodasi di MV. Glovis Daylight. Dalam melakukan pengamatan terhadap beberapa kejadian dan fakta yang terjadi selama melaksanakan pengecekan dengan Masinis 3, penulis menemukan beberapa masalah yang menyebabkan Air Conditioner bekerja tidak optimal sehingga berpengaruh pada temperature di ruang akomodasi yang dikarenakan temperature tersebut menjadi tidak normal dari biasanya.

Untuk itu penulis akan membuat hasil pengamatan dan penelitian mengenai permasalahan yang timbul, dalam hal ini diperlukan suatu pemahaman tentang prinsip kerja Air Conditioner dan alat bantu pendukung dari Air Conditioner.
C. Pembahasan Masalah

Dalam menentukan faktorfaktor kurang optimalnya kerja pada Air Conditioner, pertama peneliti menggunakan metode fishbone Analysis untuk mencari penyebab suatu permasalahan. Faktorfaktornya adalah sebagai berikut:
1.) Man/Manusia
2.) Nature
3.) Material
4.) Method

Tabel permasalahan dalam metode Fishbone

\begin{tabular}{|c|c|}
\hline Faktor yang diamati & Masalah yang terjadi \\
\hline 1. $M a n$ & 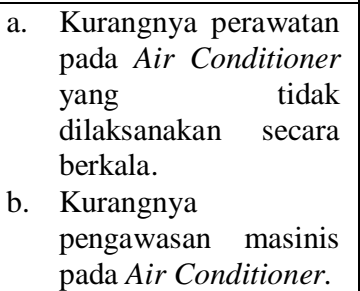 \\
\hline 2. $\quad$ Nature & $\begin{array}{l}\text { a. Adanya Fouling/ } \\
\text { endapan lumpur pada } \\
\text { kondensor. } \\
\text { b. Naiknya temperature } \\
\text { fresh water pada } \\
\text { sistem pendinginan. }\end{array}$ \\
\hline 3. Material & $\begin{array}{l}\text { a. Adanya kebocoran } \\
\text { pada katup dan } \\
\text { flange.. } \\
\text { b. Tidak kedapnya ruang } \\
\text { pendingin dan zat } \\
\text { yang didinginkan } \\
\text { akibat kebocoran pada } \\
\text { Ruber Gasket. }\end{array}$ \\
\hline 4. Method & $\begin{array}{l}\text { a. Prosedur perawatan } \\
\text { yang belum optimal. } \\
\text { b. Kurang berjalannya } \\
\text { standard operational } \\
\text { procedur (SOP) di } \\
\text { atas kapal. }\end{array}$ \\
\hline
\end{tabular}

Tabel digunakan untuk mengelompokan pokok penyebab permasalahan yang terjadi.

Permasalahan tersebut dapat disusun sebagaimana pada diagram Fishbone berikut: 
Peningkatan Kerja Pada Air Conditioner Dalam Menjaga Suhu Ruang Akomodasi Di MV.Glovis Daylight

Rizqi Aditya Pratama ${ }^{a}$, Dwi Prasetyo ${ }^{b}$

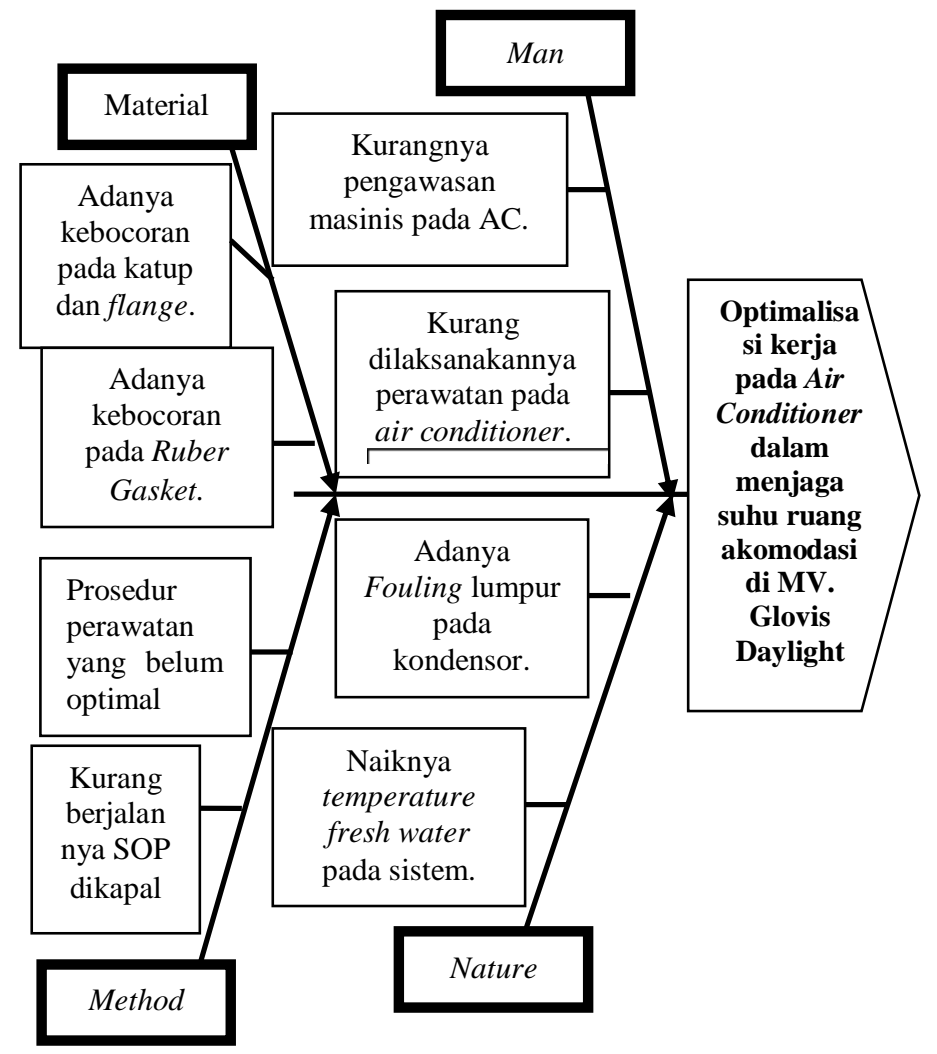

Diagram Fishbone Analysis

Berikut penjelasan dari faktor-faktor yang menyebabkan kegagalan sistem kerja Air Conditioner:

1. Faktor $m a n / m a n u s i a$.

a. Kurangnya perawatan pada Air Conditioner yang tidak dilaksanakan secara berkala.

Berdasarkan masalah yang terjadi yaitu kurang optimalnya kerja pada Air Conditioner yang tidak dilaksanakan secara berkala. Salah satu kelalaian ketika perawatan pada Air Conditioner yaitu tidak dilaksanakannya pergantian filter untuk Air Conditioner dan tidak dilakukan greasing pada motor blower. Hal ini menyebabkan udara yang masuk ke akomodasi menjadi kotor dan tidak nyaman serta tidak dilaksanakannya greasing pada motor blower akan menyebabkan shaft pada

2. Faktor nature/alam.

motor akan mengalami kepanasan dan dapat menimbulkan keausan dan juga terbakar.

b. Kurangnya pengawasan masinis pada Air Conditioner.

Ada beberapa faktor yang mempengaruhi kurangnya kesadaran para crew mesin terhadap Air Conditioner adalah :

1). Faktor komunikasi yang buruk.

Suatu tim kerja di atas kapal haruslah memiliki interaksi yang baik, karena itu komunikasi sangatlah penting dalam sebuah tim kerja agar memperoleh keberhasilan.

2). Faktor kelelahan kerja.

Akibat logis dari suatu kelelahan adalah pekerjaan yang berat untuk diselesaikan, sehingga berdampak terhadap individu yang bersangkutan adalah penurunan kinerja. Semakin sering dan beratnya pekerjaan, kelelahan yang dihadapi oleh seluruh crew kapal berakibat tidak memiliki semangat untuk melakukan pekerjaan.

a. Adanya Fouling/ endapan lumpur pada kondensor.

Adanya faktor tersebut menyebabkan tersumbatnya pipa-pipa kondensor ialah karena terdapat kotoran, endapan-endapan lumpur dan kerak-kerak yang menempel pada permukaan dan bagian dalam dari pipa- 
pipa kondensor. Seperti yang

dialami penulis saat melaksanakan praktek laut. Banyak terdapat endapan dan kotoran serta kerak yang menempel pada bagian dalam kondensor, sehingga menghambat proses kondensasi.

Penulis melakukan pengamatan tentang terjadinya endapan pada pipa-pipa kondensor adalah saat air tawar pada low termperature expansion tank kotor hal itu disebabkan karena kurang ditambahnya chemical sehingga air tawar ketika dilakukan water test terdapat ppm yang tinggi pada CWT dan Chloride Test yang menyebabkan terjadinya korosi serta endapan pada pipa kondensor dan kurang dilakukannya drain out agar air tawar selalu sirkulasi sehingga mengakibatkan kotoran lumpur tersebut masuk kedalam pipa.

b. Naiknya temperature fresh water pada sistem pendinginan.

Naiknya temperature fresh water dimana seharusnya temperature pada fresh water $36^{\circ} \mathrm{C}$. Sedangkan adanya faktor alam sehingga temperature pada fresh water naik antara $40^{\circ} \mathrm{C}-45^{\circ} \mathrm{C}$ yang dikarenakan temperature pada air laut juga naik. Hal ini dikarenakan kapal yang penulis alami melewati musim panas sehingga temperature pada air laut naik.

\section{Faktor Material}

a. Adanya kebocoran pada katup dan sambungan flange.

Berdasarkan masalah diatas bahwa didalam sistem installasi Air Conditioner refrigerant sangatlah penting, karena refrigerant sendiri digunakan sebagai media pendingin untuk penyerapan panas pada ruang sekitar atau pada evaporator. Berdasarkan pengalaman yang penulis dapatkan refrigerant tersebut mengalami kehilangan hal ini disebabkan karena adanya kebocoran pada tiaptiap katup di Air Conditioner. Kebocoran pada katup dan flange ini termasuk dalam faktor material dikarenakan bahan dari katup dan flange itu sendiri memiliki kualitas yang kurang bagus sehingga dengan berjalannya waktu bahan dari katup tersebut kualitasnya akan menurun dan menyebabkan kebocoran.

b. Tidak kedapnya ruang pendingin dan zat yang didinginkan akibat kebocoran pada Ruber Gasket.

Selain perihal adanya kebocoran pada katup dan nipple karena faktor material, kemudian penulis mengemukakan hasil dari tabel permasalahan yang diperoleh melalui metode fishbone terdapat permasalahan lain yang mana diakibatkan oleh ketidak kedapan antara ruang pendingin dengan ruang yang didinginkan diakibatkan oleh ukuran Rubber Gasket yang dipasang tidak sesuai dengan 
Peningkatan Kerja Pada Air Conditioner Dalam Menjaga Suhu Ruang Akomodasi Di MV.Glovis Daylight

Rizqi Aditya Pratama ${ }^{a}$, Dwi Prasetyo

ukuran yang semestinya, ini terjadi akibat ketersediaan suku cadang berupa Rubber Gasket tidak ditemukan atau dengan kata lain tidak ada Spare Part.

4. Faktor method/metode pengoperasian.

a. Prosedur perawatan yang belum optimal.

Adapun selain faktor dari man, nature, dan material yaitu faktor method. Faktor method/nmetode. Faktor method tersebut tidak dilaksanakan sesuai SOP sehingga pada kenyataan diatas kapal tempat penulis melakukan penelitian, perawatan yang dilakukan terhadap Air Conditioner tidak sesuai dengan PMS (Plan Maintenance System) yang ada dikapal. Masinis dikapal kadang melakukan perawatan tidak sesuai jadwal yang telah ditentukan. Masinis dikapal juga sering melakukan perawatan dan perbaikan tidak berdasarakan pada manual book, hal ini dikarenakan kurangnya kesadaran bahwa penggunaan manual book untuk penanganan sebuah masalah dan perawatan sangatlah penting, karena manual book merupakan acuan yang dibuat oleh maker yang didalamnya berisi tentang semua yang berhubungan dengan mesin tersebut. Hal ini sangat berpengaruh terhadap cara perawatan Air Conditioner, yang seharusnya dapat diantisipasi tetapi semakin menjadi masalah yang lebih besar bahkan menjadi masalah yang fatal.

b. Kurang berjalannya standard operational procedur (SOP) di atas kapal.

Standard operational procedur (SOP) di atas kapal yang seharusnya dilakukan dan diterapkan ketika melakukan perawatan terhadap mesin dalam hal ini adalah Air Conditioner mesin pendingin ternyata selama peneliti melakukan praktek kurang berjalan dengan semestinya. Masinis dikapal cenderung melakukan perawatan pada Air Conditioner dengan berpatok atau berpedoman pada pengalaman yang masisnis punya dengan tidak mengikuti SOP yang ada. Hal ini yang berpengaruh pada kerja dari Air conditioner, sehingga membuat mesin pendingin yaitu Air Conditioner ini tidak bekerja dengan optimal.

2. Dampak kurang optimalnya kerja pada Air Conditioner.

Selama penelitian yang dilaksanakan penulis di MV. Glovis Daylight, penulis menemukan beberapa dampak negatif akibat dari kurang optimalnya kerja Air Conditioner yang berakibat pada semua crew. Adapun dampak yang ditimbulkan akibat kurang optimalnya kerja Air Conditioner yaitu:

1. Dampak Internal

Dampak tersebut seperti kerugian yang cukup besar akibat bocornya refrigerant di dalam sistem pendinginan. 
Kemudian dampak akibat dari adanya endapan di dalam kondensor yaitu menimbulkan timbulnya kerak ataupun kotoran sehingga menyebabkan terlambatnya proses kondensasi yang mengganggu proses pada sistem pendingin sehingga kerja Air Conditioner tidak optimal. Serta dampak negatif akibat kurangnya pengawasan pada masinis atau crew kapal yaitu menyebabkan banyak masalah terhadap komponen-komponen pada bagian Air Conditioner.

2. Dampak Eksternal

a. Dampak bagi crew

Kurangnya rasa nyaman di dalam akomodasi karena temperature ruangan tidak mencapai dengan kebutuhan yang di inginkan. Sehingga menyebabkan crew saat bekerja maupun beristirahat didalam ruangan tidak mendapatkan kenyamanan.

\begin{tabular}{|c|c|c|c|}
\hline \multicolumn{2}{|c|}{ INPUT } & \multicolumn{2}{c|}{ OUTPUT } \\
\hline $\mathrm{A}$ & $\mathrm{B}$ & $A N D$ & OR \\
\hline 0 & 0 & 0 & 0 \\
\hline 1 & 0 & 0 & 1 \\
\hline 0 & 1 & 0 & 1 \\
\hline 1 & 1 & 1 & 1 \\
\hline
\end{tabular}

b. Dampak lingkungan

Dapat menyebabkan pemanasan global. Serta dampak lainnya yaitu pada perangkat elektronik, seperti komputer, panel listrik, alat navigasi, kabel-kabel dan lainnya itu akan menyebabkan terbakar atau rusak dikarenakan temperature terlalu panas.
c. Dampak bagi kesehatan
1). Menimbulkan rasa panas dan dehidrasi
2). Alergi dan infeksi saluran pernapasan

3. Upaya meningkatkan kurang optimalnya kerja pada Air Conditioner

Dalam upaya meningkatkan kurang optimalnya kerja pada Air Conditioner, penulis menganalisa kembali penyebab permasalahan yang sudah didapat melalui metode fishbone analysis dengan menggunakan metode foult tree analysis (FTA) dan mengkombinasikan dengan gerbang $A N D$ dan $O R$ sehingga perlu membuat gambar diagram pohon kesalahan terlebih dahulu. Penulis memilih metode fault tree analysis ini karena ingin mencari akar dari permasalahan yang penulis alami selama di kapal.

Tabel kebenaran AND dan $O R$

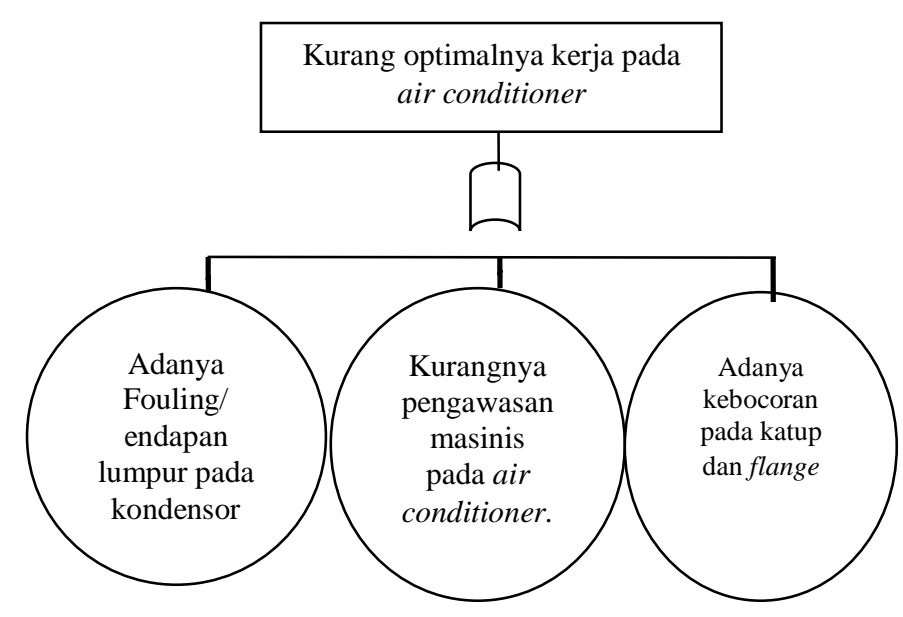

Bagan Fault Tree Analysis.

Gerbang $O R$ akan berlogika 1 atau keluarannya akan berlogika 1 apabila salah satu masukannya 1, namun apabila semua masukannya berlogika 0 maka keluarannya akan berlogika 0 . Dari penjelasan 
Peningkatan Kerja Pada Air Conditioner Dalam Menjaga Suhu Ruang Akomodasi Di MV.Glovis Daylight

Rizqi Aditya Pratama ${ }^{a}$, Dwi Prasetyo

gerbang $O R$ bisa dijelaskan tabel di bawah bahwa jika salah satu komponen terjadi kerusakan maka akan menyebabkan kurang optimalnya kerja Air Conditoner. Berikut ini adalah tabel kebenaran yang akan menunjukan apa saja yang mengakibatkan kurang optimalnya kerja pada Air Conditioner.

Tabel kebenaran

\begin{tabular}{|c|c|c|c|}
\hline $\begin{array}{c}\text { Adanya } \\
\text { Fouling/e } \\
\text { ndapan } \\
\text { lumpur } \\
\text { pada } \\
\text { kondensor }\end{array}$ & $\begin{array}{c}\text { Kurangnya } \\
\text { pengawasan } \\
\text { masinis } \\
\text { pada air } \\
\text { conditioner. }\end{array}$ & $\begin{array}{c}\text { Adanya } \\
\text { kebocoran } \\
\text { pada katup } \\
\text { dan flange }\end{array}$ & Output \\
\hline 0 & 0 & 0 & 0 \\
\hline 1 & 0 & 0 & 1 \\
\hline 1 & 1 & 0 & 1 \\
\hline 1 & 1 & 1 & 1 \\
\hline
\end{tabular}

Berikut penulis akan jabarkan satu persatu secara detail cabangcabang permasalahan tentang penyebab kurang optimalnya kerja Air Conditioner.

\section{a. Adanya Fouling/endapan lumpur pada kondensor.}

Terjadinya fouling/endapan lumpur pada kondensor.

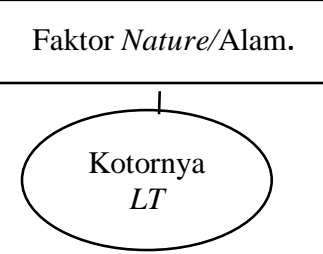

Dari pohon kesalahan diatas dapat diambil kesimpulan bahwa kotornya Low Temperature Cooler maupun kotornya LT pada Expansion Tank. Hal itu disebabkan karena kurang ditambahnya chemical sehingga air tawar ketika dilakukan water test terdapat ppm yang tingi pada pengetesan CWT dan Chloride yang menyebabkan terjadinya korosi serta endapan pada pipa kondensor dan kurang dilakukannya drain out.
Upaya yang harus dilakukan untuk mencegah adanya fouling/endapan lumpur pada kondensor adalah:

1) Merencanakan pembersihan kondensor sesuai PMS.

2) Secara rutin atau setiap UMA checked melakukan pengecekan temperature masuk dan keluar dari kondensor.

3) Segera lakukan pergantian air pendingin pada LT Expansion Tank dan melakukan water test pada sistem pendinginan tersebut.

b. Kurangnya pengawasan masinis pada Air Conditioner.

Kurangnya pengawasan masinis pada air conditioner

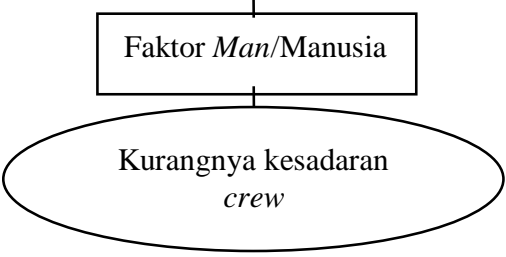

Dari pohon kesalahan diatas dapat disimpulkan bahwa penyebab kurangnya pengawasan masinis pada Air Conditioner yaitu dapat disebabkan karena adanya faktor man/manusia seperti:

1) Faktor komunikasi yang buruk.

Suatu tim kerja di atas kapal haruslah memiliki interaksi yang baik, karena itu komunikasi sangatlah penting dalam sebuah tim kerja agar memperoleh keberhasilan.

2). Faktor kelelahan kerja.

Akibat logis dari suatu kelelahan adalah pekerjaan yang berat untuk diselesaikan, sehingga berdampak terhadap individu yang bersangkutan adalah penurunan kinerja.

Upaya yang dilakukan untuk meningkatkan kurangnya pengawasan pada masinis terhadap Air Conditioner : 
a) Dengan melakukan pengawasan terhadap Air Conditioner setiap UMA Checked yaitu seperti pengecekan pada pressure, temperature, dan kondisi di local side.

b) Melakukan penerapan sistem PMS (Plan Maintenance System) pada masinis sehingga masinis lebih tahu dengan kondisi Air Conditioner tersebut.

c) Melakukan Tool Box Meeting sebelum bekerja sehingga mengingatkan dan saling berdiskusi tentang masalah yang terjadi pada setiap harinya. Dengan ini akan mengingatkan masinis yang bertanggung jawab pada mesin tersebut dan juga pada semua crew engine.

c. Adanya kebocoran pada katup dan flange.

Kebocoran pada katup dan flange

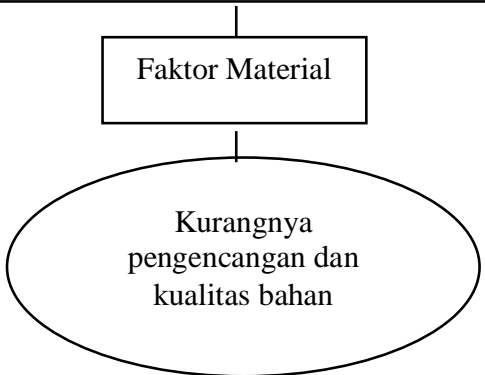

Dari pohon kesalahan diatas dapat disimpulkan bahwa penyebab kebocoran pada katup dan flange yaitu dikarenakan faktor material dimana kurangnya pengencangan dan kualitas bahan. Kurangnya pengencangan menyebabkan kebocoran karena setiap sambungan flange maupun katup serta kualitas bahan itu sendiri sangat mempengaruhi dikarenakan bahan termasuk dalam faktor material yaitu dengan berjalannya waktu bahan pasti akan mengalami penurunan kualitas.
Upaya yang dilakukan untuk mencegah terjadinya kebocoran pada katup dan flange:

1) Melakukan pengecekan pada tiaptiap katup maupun flange dengan menggunakan halogen leak detector.

2) Mengganti katup ataupun flange yang mengalami kebocoran dengan yang baru.

3) Melakukan request order untuk spare part yang baru dan original agar memiliki kualitas yang bagus untuk spare.

Adanya fouling/endapan lumpur pada kondensor adalah faktor yang paling sering muncul yaitu faktor alam, sehingga timbulnya korosi pada pipa pendingin kondensor seperti yang telah dipaparkan pada pembahasan melalui metode fishbone analysis. Penulis menganalisa kembali faktor penyebab tersebut dengan menggunakan metode fault tree analysis untuk menemukan basic event dan mengggunakannya untuk menentukan upaya mengatasi kurang optimalnya kerja pada Air Conditioner. Penulis membentuk cut set dan dapat disimpulkan bahwa faktor dominan yang paling mempengaruhi kurang optimalnya kerja Air Conditioner adalah faktor alam yaitu, Adanya fouling/endapan pada kondensor.

\section{SIMPULAN}

\section{A. Kesimpulan}

Berdasarkan uraian dan pembahasan masalah dalam penelitian ini, maka penulis dapat menarik kesimpulan yang sesuai dengan kondisi dan kenyataan yang terjadi diatas MV. Glovis Daylight. Dalam kondisi kurang optimalnya kerja Air Conditioner dalam menjaga suhu ruang akomodasi, 
Peningkatan Kerja Pada Air Conditioner Dalam Menjaga Suhu Ruang Akomodasi Di MV.Glovis Daylight

Rizqi Aditya Pratama ${ }^{a}$, Dwi Prasetyo

maka kesimpulan tersebut adalah sebagai berikut:

1. Faktor penyebab kurang optimalnya kerja Air Conditioner guna menjaga suhu ruang akomodasi adalah adanya fouling/endapan lumpur pada kondensor yang diakibatkan karena kotornya Low Temperature Cooler, timbulnya korosi pada tube side kondensor karena terbawa sistem aliran pendingin air tawar yang masuk kedalam kondensor.

2. Dampak yang terjadi akibat kurang optimalnya kerja Air Conditioner adalah refrigerant/zat pendingin yang melalui kondensor tidak dapat mengkondensikan dengan baik sehingga keluaran dari kondensor tidak sepenuhnya menjadi liquid hal ini yang menyebabkan kerja Air Conditioner menjadi tidak opimal dan crew merasa tidak nyaman karena suhu ruang akomodasi terasa panas.

3. Upaya agar sistem kerja Air Conditioner dapat bekerja dengan optimal yaitu dengan melaksanakan perawatan pada Air Conditioner sesuai PMS (Plan Maintenance System) serta melaksanakan pembersihan dan pengecekan secara berkala pada tiap-tiap komponen Air Conditioner.

B. Saran

Dari hasil penelitian yang telah didapat, penulis akan menyampaikan saran-saran yang mungkin dapat berguna dalam upaya proses perawatan pada Air Conditioner agar proses pendinginan pada mesin tersebut dapat berjalan secara lancar dan baik serta membuat crew merasa nyaman ketika didalam akomodasi maupun ruangan. Adapun saran- saran yang dapat disampaikan oleh penulis sebagai berikut :

1. Sebaiknya melaksanakan pengecekan, perawatan serta pembersihan pada Air Conditioner setiap bulan secara berkala. Penulis dalam melaksanakan UMA Check maupun night patrol juga menganalisa keadaan dan kondisi seperti adanya kebocoran atau tidak pada Air Conditioner tersebut, mencatat temperature pada kondensor apakah ada penyimpangan yang berlebih, mencatat pressure pada Air Conditioner seperti pressure pada discharge kompressor maupun suction serta mengecek level freon/refrigerant pada sight glass. Hal tersebut sangatlah penting yang dapat mempengaruhi kerja Air Conditioner.

2. Sebaiknya selalu teliti dan hatihati dalam melaksanakan dinas jaga kamar mesin yaitu UMA Check. Catat jurnal Log book sesuai dengan apa yang ada pada setiap permesinan dan lakukan pengecekan tiap-tiap komponen pada Air Conditioner agar dapat terkontrol dengan baik, serta peka terhadap keanehan maupun kejanggalan yang tidak sesuai pada mestinya. Segeralah melapor pada masinis jaga saat itu agar masinis jaga dapat segera menganalisa dan mengambil tindakan.

3. Seharusnya dalam melaksanakan upaya, perhatikan waktu berkala perawatan permesinan untuk merencanakan pembersihan pada Air Conditioner sesuai PMS terutama setelah kapal akan memasuki wilayah 


\begin{abstract}
perairan panas maka Air Conditioner tersebut lebih diperhatikan sebab akan berjalan secara terus menerus sehingga kemungkinan besar menyebabkan banyak masalah yang terjadi pada tiap-tiap komponen pada Air Conditioner. Serta lebih memperhatikan semua safety device dengan lebih seksama pada tiap-tiap bagian agar sistem pendinginan dapat berjalan dengan optimal.
\end{abstract}

\section{DAFTAR PUSTAKA}

Bracciano, Alfred F, 2000, Modern Refrigeration and Air Conditioning, Tinley Park, Illinois Amerika Serikat.

Instruction Manual Book, 2014, Heating, Ventilating and Air Conditioning System Provision Refrigerating System, HI Air Korea CO., LTD, Korea Selatan.

Liana, 2012, Suhu, Dikutip dari

https://caridokumen.com/download/ bab-ii-dasar-teori-21-tinjauan-teori211-pengertian-suhu5a463c65b7d7bc7b7afaaf53_pdf, 31 Mei.

Mukhtar, 2013, Metode Penelitian Deskriftif Kualitatif, GP Press Group, Jakarta.

Narbuko, Cholid dan Abu Achmadi, 2010, Metodologi Penelitian, Bumi Aksara, Jakarta.

Poerdwadarminta W.J.S., Tahun 1997, Kamus Bahasa Indonesa, Badan Penerbit Universitas Lampung, Sumatra Selatan.

Putri, Elisa Anita, 2011. Suhu dan Kalor, Balai Pustaka, Jakarta.

Sugiyono, 2009, Metode Penelitian Kuantitatif, Kualitatif, dan $R \& D$, Penerbit Alfabeta, Bandung.

Suryana, 2010, Metode Penelitian Model Praktis Penelitian Kuantitatif dan Kualitatif, UPI, Bandung.
Tim Penyusun Pusat Kampus, Tahun 1994, Kamus Besar Bahasa Indonesia, Balai Pustaka, Jakarta.

Winardi, 1999, Badan Penerbit Universitas Lampung, Sumatera Selatan. 